\title{
METODE PENGENALAN POLA TRABEKULA MANDIBULA PADA RADIOGRAF PERIAPIKAL DIGITAL UNTUK DETEKSI DINI RISIKO OSTEOPOROSIS
}

\author{
Sri Lestari dan Evrita Lusiana Utari \\ Minat Studi Teknik Elektromedis \\ Program Studi Teknik Elektro Universitas Respati Yogyakarta \\ Email: lestari2411@gmail.com.
}

\begin{abstract}
Osteoporosis is a sistemic skeletal disease. Osteoporosis examination using the gold standard determined by WHO, namely DEXA, is relatively expensive and the result can not show the bone microarchitecture. Meanwhile, the probability of advanced age women to visit a dentist is relatively high. If the condition of bone mass density which indicate osteoporotic condition can be recognized from the trabecullar pattern of mandible, so the dentist can participate in early detection of a patient having a risk of osteoporosis. The objective of this research is to get the pattern recognition method which can be applied to digital periapical radiograph that characterize the bone mass density condition. Combination of Sobel's edge detection with the binary image has been applied to the image, producing an image showing the mandible trabecullar pattern visually. Supported by fractal dimension value and find local maxima in the binary image, the pattern can be better distinguished for each condition of osteoporosis, osteopenia, and normal. The value of fractal dimension and find maxima is positively correlated with the bone mass density.
\end{abstract}

Keywords: osteoporosis, bone mass density, radiograph, trabecullar, pattern recognition.

\begin{abstract}
ABSTRAK
Osteoporosis adalah suatu penyakit skeletal sistemik. Pemeriksaan osteoporosis dengan metoda standar baku emas yang ditetapkan WHO, yaitu DEXA, relatif mahal dan hasilnya tidak dapat memberikan informasi tentang mikroarsitektur tulang. Sementara itu, peluang lansia untuk mengunjungi dokter gigi relatif tinggi. Jika kondisi densitas massa tulang yang menjadi indikator kondisi osteoporosis dapat dikenali dari pola trabekula mandibula, maka dokter gigi memiliki peluang untuk berperan dalam deteksi awal resiko pasien mengalami osteoporosis. Adapun tujuan dari penelitian ini adalah untuk memperoleh metode pengenalan pola citra radiograf periapikal digital yang mencirikan kondisi densitas massa tulang. Telah dikombinasikan metode deteksi tepi Sobel dengan binerisasi citra, sehingga menghasilkan tampilan visual mengenai pola trabekula mandibula. Di dukung dengan nilai fraktal dimensi dan deteksi maksimal lokal pada citra biner yang dihasilkan, maka semakin dapat dibedakan pola trabekula mandibula pada masing-masing kondisi osteoporosis, osteopenia, dan normal. Nilai fraktal dimensi dan hasil deteksi maksimal lokal berkorelasi searah dengan densitas massa tulang.
\end{abstract}

Kata kunci: osteoporosis, densitas massa tulang, radiograf, trabekula, pengenalan pola. 


\section{PENGANTAR}

Osteoporosis adalah suatu penyakit skeletal sistemik yang dicirikan oleh penurunan massa tulang, perubahan arsitektur tulang, dan memberikan konsekuensi klinis berupa rentan terhadap fraktur (patah tulang) dengan trauma yang ringan atau tanpa trauma. Pada umumnya, fraktur terjadi pada tulang yang memiliki banyak trabekula, yaitu pergelangan tangan (wrist), tulang belakang (spine), dan pangkal paha (femur). Kontribusi osteoporosis terhadap angka kesakitan (morbiditas) dan angka kematian (mortalitas) adalah relatif rendah, Akan tetapi, fraktur osteoporosis membuat penderitanya merasa sakit dan menderita, serta mempengaruhi kondisi sosial ekonomi dalam hal sistem perawatan kesehatan dan masyarakat pada umumnya (Adams, 2008).

Hasil analisa data risiko Osteoporosis pada tahun 2005 dengan jumlah sampel 65.727 orang yang dilakukan oleh Puslitbang Gizi Departemen Kesehatan RI dan sebuah perusahaan nutrisi dengan metode pemeriksaan DMT (densitas massa tulang) menunjukkan bahwa 2 dari 5 penduduk Indonesia memiliki risiko untuk terkena osteoporosis (HTA Indonesia, 2005). Salah satu dari program pengendalian osteoporosis oleh Kementrian Kesehatan (Kemenkes) RI adalah penemuan dan tatalaksana kasus (termasuk deteksi dini osteoporosis). Tujuan dari program ini adalah untuk pelaksanaan deteksi dini pada kelompok masyarakat beresiko osteoporosis, sehingga diharapkan dapat menurunkan angka kesakitan dan kematian akibat osteoporosis (Kemenkes RI, 2008).

Pemeriksaan bone mineral density (BMD) pada kelompok yang beresiko tinggi merupakan upaya penting untuk mengurangi prevalensi osteoporosis di Indonesia (Priyana, 2007). Dual Energy X-Ray Arbsorptiometry (DEXA) merupakan metode pemeriksaan BMD yang dijadikan standar baku emas oleh organisasi kesehatan dunia (WHO) (Blake dan Fogelman, 2007).
Sementara itu, beberapa penelitian di bidang kedokteran gigi membuktikan bahwa terjadinya osteoporosis pada tulang paha dan tulang belakang, akan diindikasikan juga dengan osteoporosis pada tulang rahang.

Hasil pengukuran densitas massa tulang menggunakan teknik DEXA adalah nilai BMD dan T-score yang mencerminkan kepadatan tulang berdasarkan kandungan mineral dalam tulang. Menururt D'Elia et al (2009), perbedaan antara korteks dan trabekula tidak dapat ditunjukkan melalui hasil DEXA. Oleh karena itu, diperlukan metode yang dapat mencerminkan mikro arsitektur tulang sebagai indikator kualitas tulang selain densitas massa tulang. Disamping itu, metode tersebut diharapkan dapat mudah diaplikasikan dan terjangkau, mengingat ketersediaan perangkat DEXA dan biaya pemeriksaan yang relatif mahal menjadi salah satu faktor yang menurunkan kegunaan DEXA untuk screening tahunan wanita post menopause sebagaimana yang dinyatakan oleh Licks et al(2010).

Taguchi et al (2007) menyebutkan bahwa wanita postmenopause yang mengalami perubahan pada mandibulanya dimungkinkan beresiko mengalami osteoporosis atau memiliki BMD vertebral yang rendah. Hasil tersebut didukung olah hasil penelitian yang dilakukan oleh White et al (2005) yang menyebutkan bahwa perubahan pada struktur trabekula yang dideteksi dari radiograf dental dapat menjadi tambahan informasi klinis dalam prediksi fraktur sendi panggul (hip fracture) pada wanita lansia.

Potensi lansia untuk mengunjungi dokter gigi guna mendapatkan perawatan gigi berlubang, pembuatan protesa, atau perawatan penyakit periodontal adalah lebih besar daripada untuk memeriksakan diri ke rumah sakit untuk perawatan osteoporosis (Ishii et al, 2007). Radiografi dental merupakan cara paling sering digunakan untuk keperluan perawatan gigi, diperlukan pengambilan radiograf untuk penegakan 
diagnosa dan penentuan rencana perawatan (Taguchi et al, 2007; White, 2002 disitasi oleh Watanabe et al, 2007).

Pemeriksaan dengan radiografi periapikal relatif tidak mahal dan ketersediaan perangkatnya relatif lebih luas. Tulang trabekula rahang dapat divisualisasikan dalam radiograf periapikal. Pola tulang trabekula rahang dapat dihubungkan dengan kondisi tulang pada bagian kerangka yang lain di dalam tubuh pada tingkat mikrostruktur (Licks et al, 2010).Kepentingan untuk memperoleh indikator osteoporosis dari radiograf dental, maka penerapan metode ini dilakukan pada regio trabekula mandibula yang merupakan bagian dari sistem skeletal dalam tubuh manusia dan digambarkan dengan jelas menggunakan radiograf periapikal.

Teknik diagnostik menjadi hal yang penting dalam upaya untuk pencegahan osteoporosis. Jika osteoporosis dapat dideteksi pada fase awal, maka proses penanganan terhadap patologi ini akan lebih mudah (Watanabe, 2007). Oleh karena itu, upaya-upaya deteksi awal kejadian osteoporosis sangat menarik untuk dikaji. Adanya korelasi antara tekstur trabekula pada radiograf dental dengan nilai BMD hasil pengukuran DEXA memungkinkan dokter gigi untuk turut berperan dalam mendeteksi resiko pasien menderita osteoporosis (Geraets et al., 2008; White et al., 2005). Penelitian ini dilakukan untuk memperoleh metode pengenalan pola dari citra radiograf periapikal digital untuk dapat membedakan pola trabekula mandibula yang mengindikasikan kondisi osteoporosis pada tulang belakang(lumbar spine) dan panggul(hip).

Penelitian mengenai deteksi osteoporosis berdasarkan perubahan pola trabekula mandibula telah dilakukan oleh White et al (2005) untuk mengetahui hubungan antara perubahan pola trabekula pada rahang dengan fraktur panggul (hip fracture) pada wanita California. Geraets et al (2008) menganalisis pengaruh pemilihan region of interest (ROI) di rahang atas dan rahang bawah dengan atau tanpa mengikutsertakan gigi terhadap kemampuan prediksi BMD pada tulang paha dan tulang belakang. Le Corroller et al (2011) mengkombinasikan parameter tekstur dengan metode fractal dimension, matriks cooccurence, dan run length untuk selanjutnya dikorelasikan dengan hasil pengukuran DEXA dan uji mekanik pada kadaver tulang paha. Kombinasi tersebut terbukti dapat meningkatkan keakuratan prediksi osteoporosis daripada prediksi berdasarkan BMD saja.

Studi korelasi antara parameter tekstur trabekula mandibula dengan nilai densitas massa tulang menggunakan radiograf periapikal digital pada regio anterior menunjukkan adanya korelasi antara kedua variabel tersebut (Lestari, dkk. 2012). Adapun subyek dalam penelitian ini adalah wanita Indonesia post-menopause. Metode analisis pengenalan pola yang diaplikasikan terhadap radiograf periapikal mandibula adalah analisis visual, fraktal dimensi, dan deteksi maksimal lokal pada citra biner yang diperoleh dari kombinasi metode deteksi tepi dan binerisasi citra pada citra radiograf periapikal.

\section{Material dan Metode Penelitian}

Adapun sampel penelitian adalah radiograf periapikal dan hasil pemeriksaan BMD dengan scan DEXA yang memenuhi quality assurance dari 18 orang subyek. Proses pengolahan citra dilakukan terhadap citra radiograf periapikal, sehingga dihasilkan data visual berupa citra biner, dan data numerik berupa nilai fraktal dimensi $(D)$ dan nilai deteksi maksimal lokal. Adapun nilai kepadatan massa tulang hasil scan DEXA adalah nilai BMD pada sendi panggul (hip) dan ruas tulang belakang (lumbarspine). Datahasil pemeriksaan densitas massa tulang dilakukan di RSUP dr. Sardjito menggunakan perangkat DEXA GE Lunar Prodigy primo. Setting tegangan dan kuat arus listrik 
masing-masing adalah $76 \mathrm{kV}$ dan 1,5 mA, serta waktu paparan 1 menit 14 detik untuk pemeriksaan femoral, dan 1 menit 27 detik untuk pemeriksaan lumbar spine. Interpretasi hasil scan DEXA dilakukan oleh dokter/ radiologis. Proses pengolahan citra radiograf dilakukan di Laboratorium Elektromedik Universitas Respati Yogyakarta.

Masing-masing subyek memiliki hasil scan radiografi periapikal dan DEXA. Hasil Proses pengolahan citra diawali dengan seleksi citra untuk diolah, yaitu citra radiograf periapikal yang mewakili subyek yang osteoporosis, osteopenia, dan normal pada kedua tempat scan DEXA, yaitu panggul (hip)dan tulang belakang(lumbar spine), masing-masing satu (1) buah citra. Seleksi ROI dilakukan untuk mengamati pola trabekula mandibula pada regio anterior. Citra radiograf periapikal yang dihasilkan berukuran 1252 piksel x 1645 piksel, $1 \mathrm{~mm}$ pada citra mewakili 39 piksel. Proses seleksi ROI dilakukan dengan bantuan dokter gigi untuk menentukan lokasi ROI. Pengolahan dilakukan terhadap ROI yang berukuran 300 piksel x 200 piksel yang dilakukan menggunakan Matlab 2010a. Adapun proses pengolahan citra dan analisis citra selanjutnya menggunakan software Image J. Deteksi tepi dilakukan dengan menggunakan Detektor Tepi Sobel untuk menonjolkan perubahan intensitas yang tajam dalam citra. Dua buah kernel konvolusi 3x3 digunakan untuk menghasilkan derivatif vertikal dan horizontal, sebagaimana yang ditunjukkan pada Gambar 1.

\begin{tabular}{|l|l|l|}
\hline 1 & 2 & 1 \\
\hline 0 & 0 & 0 \\
\hline-1 & -2 & -1 \\
\hline
\end{tabular}

\begin{tabular}{|l|l|l|}
\hline 1 & 0 & -1 \\
\hline 2 & 0 & -2 \\
\hline 1 & 0 & -1 \\
\hline
\end{tabular}

Gambar 1. Kernel konvolusi 3x3 untuk detektor tepi Sobel

Metode pengenalan pola yang dilakukan meliputi dua tahap, yaitu tahap deteksi tepi dan tahap binerisasi. Citra hasil dari proses deteksi tepi memungkinkan untuk diperolehnya visual pola trabekula yang spongy sebagaimana yang ditunjukkan pada Gambar 2. Tahap kedua dalam pengolahan citra adalah binerisasi citra. Analisis yang dilakukan terhadap hasil citra biner meliputi analisis visual, fraktal dimensi, dan deteksi maksimal lokal.

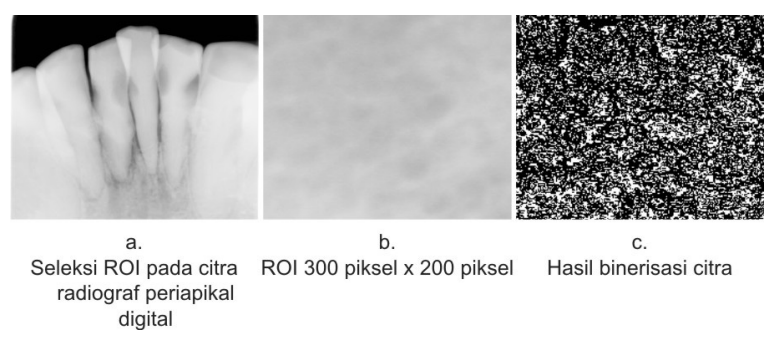

Gambar 2. Tahapan Pengolahan Citra

Deteksi maksimal lokal dilakukan untuk mendeteksi intensitas maksimal dalam suatu citra dengan membuat suatu partikel yang tersegmentasi terhadap keseluruhan citra. Metode ini, diasumsikan bahwa setiap nilai maksimum semestinya termasuk dalam sebuah partikel, yang kemudian mensegmentasi citra dengan algoritma watershed yang diterapkan pada nilai-nilai intensitas pada citra. Metode ini digunakan pemetaan jarak Euclidian.Nilai fractal dimension $(D)$ dari masing-masing citra biner yang dihasilkan digunakan untuk mengukur kompleksitas pola, dalam hal ini adalah tekstur. Nilai $D$ diperoleh dengan menghitung banyaknya kotak dengan ukuran yang semakin meningkat untuk melingkupi sebuah obyek biner dengan batas-batasnya.

\section{PEMBAHASAN}

Kondisi osteoporosis pada panggul (hip) dan tulang belakang (lumbar spine) dapat diindikasikan melalui pola trabekula pada tulang rahang karena osteoporosis merupakan penyakit sistemik pada tulang (Adams, 2008). Metode pengenalan pola yang dilakukan pada penelitian ini dapat menghasilkan citra yang dapat menampilkan pola karakteristik kondisi osteoporosis, 
osteopenia, dan normal pada panggul (hip) dan tulang belakang (lumbar spine) dari subyek.

\section{Deteksi Tepi Sobel dan Binerisasi Citra}

Berdasarkan visualisasi citra hasil dari pengolahan dilakukan, maka dapat ditampilkan perbedaan pola trabekula mandibula yang dikorelasikan dengan densitas massa tulang hasil scan DEXA. Secara visual, pola trabekula merupakan pola yang tidak beraturandan citra biner terbatas pada warna hitam dan putih karena untuk dapat membedakan pola trabekula mandibula, diperlukan pelatihan terlebih dahulu kepada pengguna (dokter gigi).

Berdasarkan Gambar 3 (a), intensitas citra biner memiliki pola yang paling kasar (rough) dibandingkan citra biner untuk subyek osteopenia dan osteoporosis. Gambar 3 (b) menunjukkan bahwa citra biner untuk subyek osteopenia memiliki homogenitas intensitas yang lebih tinggi daripada citra biner untuk subyek osteoporosis, dan lebih kecil daripada citra biner pada subyek normal. Cita biner pada subyek yang normal pada Gambar 3(c) memiliki distribusi intensitas yang homogen, sehingga memiliki pola yang paling halus (smooth) dibandingkan kedua citra biner untuk subyek osteoporosis dan osteopenia.

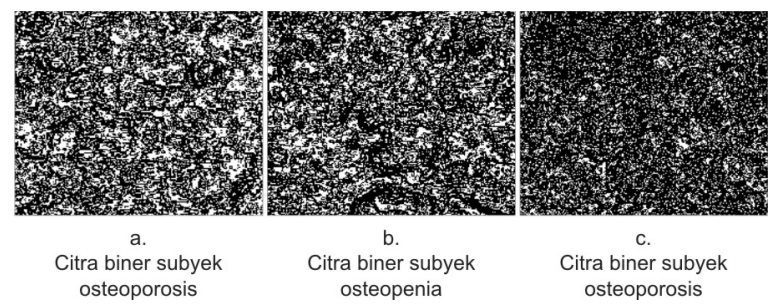

Gambar 3. Hasil pengolahan citra kombinasi metode deteksi tepi dan binerisasi citra.

\section{Deteksi Maksimal Lokal}

Gambar 4 menunjukkan pemetaan nilai maksimal lokal untuk masing-masing citra biner. Citra yang memiliki tekstur kasar (rough) akan memiliki nilai maksimal lokal yang rendah. Deteksi maksimal lokal dapat mengindikasikan adanya diskonektivitas dan penipisan trabekula. Trabekula yang terhubung baik satu sama lain dan memiliki densitas yang normal akan ditunjukkan dengan pola distribusi intensitas yang halus (smooth), sehingga dapat dideteksi jumlah maksimal lokal yang relatif tinggi.

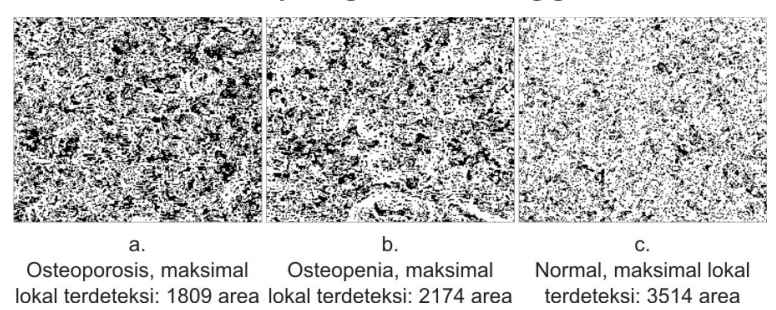

Gambar 4. Pemetaan nilai maksimal lokal citra biner

Pada Gambar 4 (a), jumlah maksimal lokal yang terdeteksi pada citra adalah 1809 area. Jumlah tersebut paling kecil dibandingkan dengan Gambar 4 (b) untuk subyek osteopenia (2174 area) dan Gambar 4 (c) untuk subyek normal (3514 area). Hal ini menunjukkan bahwa jumlah maksimal lokal yang terdeteksi berbanding lurus dengan kepadatan massa tulang yang menjadi indikator osteoporosis, sebagiamana yang ditunjukkan oleh grafik pada Gambar 5 .

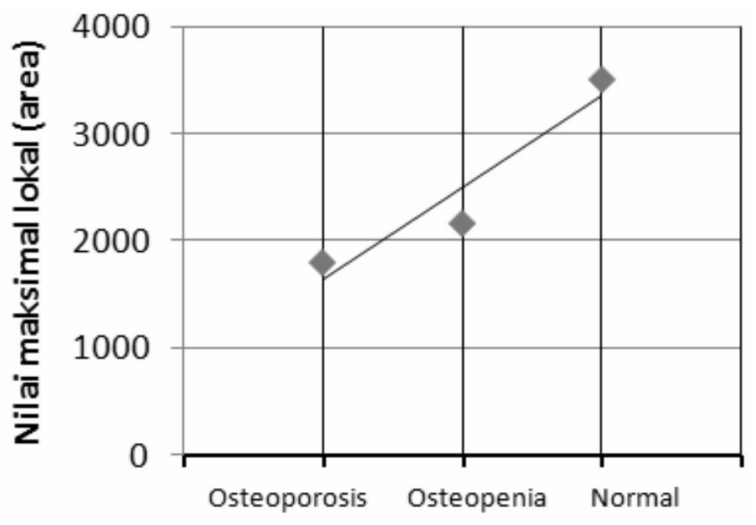

Status osteoporosis hasil scan DEXA

Gambar 5. Grafik korelasi deteksi maksimal lokal terhadap status subyek berdasarkan scan DEXA

Hasil ini sesuai dengan penelitian yang dilakukan oleh Schnitzler (2003) 
yang menyebutkan bahwa terjadi perforasi pada plate trabekula sehingga konektivitas trabekula menjadi menurun pada penderita osteoporosis. Osteoporosis disebabkan oleh ketidakseimbangan negatif dalam proses remodelling tulang, di mana aktivitas osteoklas yang meresorpsi tulang lebih tinggi daripada aktivitas osteoblas yang membentuk tulang baru (Schnitzler, 2003).

\section{Fractal dimension}

Nilai fraktal dimensi (D)untuk masingmasing status subyek disajikan dalam Tabel 1. Adapun korelasi antara nilai $D$ dengan status subyek berdasarkan hasil scan DEXA disajikan dalam Gambar 6. Berdasarkan Tabel 1 dan Gambar 6, dapat ditunjukkan bahwa nilai fraktal dimensi berbanding lurus dengan status osteoporosis. Kondisi tersebut mengindikasikan korelasi yang berbanding lurus antara nilai fraktal dimensi $(D)$ dengan kepadatan massa tulang di kedua tempat, yaitu panggul (hip) dan tulang belakang (lumbar spine). Subyek yang mengalami osteoporosis memiliki densitas massa tulang yang rendah, dan ditunjukkan dengan nilai $\mathrm{D}$ yang rendah.

Tabel 1. Nilai fraktal dimensi untuk masing status osteoporosis subyek

\begin{tabular}{ll}
\hline Status subyek & Nilai D \\
\hline Osteoporosis & $\mathrm{D}=1.9001$ \\
\hline Osteopenia & $\mathrm{D}=1.9050$ \\
\hline Normal & $\mathrm{D}=1.9144$ \\
\hline
\end{tabular}

Hasil penelitian ini sejalan dengan penelitian yang dilakukan Lestari, dkk (2012) yang menunjukkan adanya korelasi antara parameter tekstur trabekula mandibula pada radiograf periapikal digital regio anterior dengan nilai densitas massa tulang. Adapun hasil dari penelitian ini menunjukkan bahwa terdapat pola trabekula mandibula yang berbeda antara subyek yang mengalami osteoporosis, osteopenia, atau normal pada panggul (hip) dan tulang belakang (lumbar spine). Karakteristik pola dapat ditunjukkan secara visual dengan citra biner hasil metode pengenalan pola yang mengkombinasikan metode deteksi tepi dan binerisasi citra.Secara kuantitatif, nilai fractal dimension $(D)$ dapat mengindikasikan densitas massa tulang.

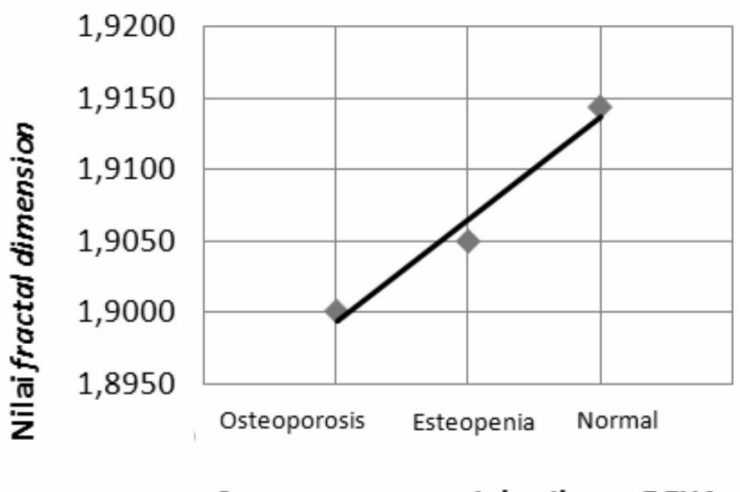

Status osteoporosis hasil scan DEXA

Gambar 7. Grafik korelasi nilai fractal dimension dengan status subyek berdasarkan scan DEXA

Didukung dengan hasil kualitatif sekaligus kuantitatif dengan find maxima, maka deteksi seseorang beresiko mengalami osteoporosis melalui radiograf periapikal digital sangat mungkin untuk dapat dilakukan oleh seorang dokter gigi. Penelitian ini merupakan penelitian awal dalam upaya untuk membangun sebuah sistem berbantuan komputer yang dapat digunakan oleh dokter gigi untuk berperan serta dalam deteksi resiko osteoporosis pada pasiennya, khususnya wanita post-menopause. Oleh karena itu, diperlukan penelitian selanjutnya untuk ekstraksi informasi fisis dan klasifikasi pola trabekula mandibula hingga dapat dibangun sebuah sistem berbantuan komputer sebagaimana yang diharapkan. Diperlukan pelatihan bagi dokter gigi untuk dapat menginterpretasikan hasil citra biner hasil dari metode yang digunakan dalam penelitian ini.

\section{SIMPULAN}

Kondisi densitas massa tulang yang menjadi indikator osteoporosis dapat ditunjukkan oleh pola trabekula mandibula 
pada regio anterior. Pengenalan pola trabekula mandibula dilakukan terhadap radiograf periapikal digital dengan mengkombinasikan metode deteksi tepi dengan binerisasi citra. Kombinasi tersebut dapat dijadikan sebagai metode pengenalan pola yang dapat membedakan pola trabekula untuk subyek yang mengalami osteoporosis, osteopenia, dan normal secara visual, didukung dengan nilai fraktal dimensi dan deteksi maksimal lokal. Nilai fraktal dimensidan hasil deteksi maksimal lokal masing-masing berkorelasi positif dengan densitas massa tulang.

Perlu dilakukan penelitian lanjutan untuk menentukan metode yang efektif dalam ekstraksi informasi fisis dari citra radiograf digital. Pemilihan region of interest lebih dari satu buah, memungkinkan untuk diperolehnya gambaran yang lebih komprehensif mengenai pola trabekula mandibula pada regio anterior untuk selanjutnya dikorelasikan dengan kepadatan massa tulang hasil pemeriksaan menggunakan DEXA.

\section{DAFTAR PUSTAKA}

Adams, J.E., 2008. Dual-Energy X-Ray Absorptiometry. In Baert, A.L., Brady, L.W., Heilmann, H.P., Knauth, M., Molls, M., Nieder, C., and Sartor, K. (eds), Medical Radiology. Diagnostic Imaging and Radiation Oncology, pp.105-124. Spinger, Heidelberg.

Blake, G.M., dan Fogelman I, 2007. “The role of DXA bone density scans in the diagnosis and treatment of osteoporosis." Postgrad Med J. 2007; 83:509-517.

D’Elia, G., Caracchini, G., Cavalli, L., dan Innocenti, P., 2009. "Bone fragility and imaging techniques". Clinical Cases in Mineral and Bone Metabolism 6:234-246.

Faber, T.D., Yoon, D.C., Service, S.K., dan White, S.C., 2004. "Fourier and wavelet analysis of dental radiographs detect trabecular changes in osteoporosis". Bone (2004) 403-411.

Ferreira, T.A. dan Rasband, W. 2010. The ImageJ User Guide, Version 1.43.

Geraets, W.G.M., Verheij, J.G.C., Van der Stelt, P.F., Horner, K., Lindh, C., Nicopoulou-Karayianni, K., Jacobs, R., Marjanovic, E.J., Adams, J.E., dan Devlin, H., 2008. "Selecting regions of interest on intraoral radiographs for the prediction of bone mineral density". Dentomaxillofac Radiol 37, 375-379.

HTA Indonesia., 2005. Penggunaan bone densitometry pada osteoporosis. Pp 1-27.

Ishii, K., Taguchi, A., Nakamoto, T., Ohtsuka, M., Sutthiprapaporn, P., Tsuda, M., Kodama, I., Kudo, Y., Sumida, H., Suei, Y., dan Tanimoto, K., 2007. "Diagnostic efficacy of alveolar bone loss of the mandible for identifying postmenopausal women with femoral osteoporosis". Dentomaxillofac Radiol 36, 28-33.

Kemenkes RI. Keputusan Menteri Kesehatan Republik Indonesia No. 1142/Menkes/ SK/XII/2008 tentang pedoman pengendalian osteoporosis.

Le Corroller, T., Halgrin, J., Pithioux, M., Guenoun, D., Chabrand, P., dan Champsaur, P., 2011. "Combination of texture analysis and bone mineral density improves the prediction of fracture load in human femurs". Osteoporos Int. DOI 10.1007/s00198011-01703-1.

Lestari, S., G.B. Suparta, and N. Kertia, 2012, "The Correlation between Texture Parameter of Mandible Trabecullar Bone with The Bone Mass Density Value", Proc. Of IEEE, The 7th ICBEMA 2012, Serpong (BSD City), November 9th-10th, 2012. 
Licks, R., Licks, V., Ourique, F., Bittencourt, H.R., and Fontanella, V., 2010. "Development of a prediction tool for low bone mass based on clinical data and periapical radiography". Dentomaxillofacial Radiology 39: 224230.

Priyana,A.2007.Peranpertandatulangdalamserum pada tata laksana osteoporosis. Universa Medicina. Juli-September 2007.Vol.26, No.3.

Schnitzler, C.M., 2003. Histomorphology of osteoporosis. In Yuehuei, H.An (ed), Orthopaedic issues in osteoporosis, pp.19-37. CRC Press LLC, Florida.

Taguchi, A., Otsuka, M., Tsuda, M., Nakamoto, T., Kodama, I., Inagaki, K., Nogochi, T., Kudo, Y., Suei, Y., dan Tanimoto, K., 2007. "Risk of vertebral osteoporosis in postmenopausal women with alterations of the mandible". Dentomaxillofac Radiol 36: 143-148.

White, S.C., Atchinson, K.A., Gornbein, J.A., Nattiv, A., Paganini-Hill, A., Service, S.K., Yoon, D.C., 2005. "Change in mandibular trabecular pattern and hip fracture rate in elderly women". Dentomaxillofac Radiol 34, 168-174.

Watanabe, P.C.A., Issa, J.P.M., de Olivera, T.M., Monteiro, S.A.C., Iyomasa, M.M., Regalo, S.C.H., dan Siessere, S., 2007. "Morphodigital study of the mandibular trabecular bone in panoramic radiograph". Int.J.Morphol 25(4):875-880.

Yasar, F., dan Akgünlü F., 2006. "The differences in panoramic mandibular indices and fractal dimension between patients with and without spinal osteoporosis". Dentomaxillofac Radiol 35, 1-9. 